\title{
PREVALENCE AND GENOTYPING OF THE HUMAN PAPILLOMAVIRUS IN THE CERVICAL SPECIMENS AMONG WOMEN OF SOUTHERN CROATIA (DALMATIA COUNTY)
}

\author{
Vanja Kaliterna1, Mariano Kaliterna², Lidija Pejkovićc ${ }^{3}$ Irena Drmić Hofman ${ }^{4}$, Šimun Anđelinović ${ }^{4}$ \\ 'Department of Medical Microbiology and Parasitology, Educational Public Health Institute of Split and Dalmatia County, Split, Croatia \\ 2Private Polyclinic, Omiš, Croatia \\ ${ }^{3}$ Gynecological Practice, Solin, Croatia \\ ${ }^{4}$ Department of Pathology and Forensic Medicine, Split University Hospital and School of Medicine, Split, Croatia
}

\section{SUMMARY}

Aim: The aim of this study was to evaluate the prevalence of HPV types in the female population with either normal or abnormal Pap smears in Southern Croatia (Dalmatia County) and to evaluate the distribution of HPV types and their association with different cytological findings.

Methods: During one year period, we routinely screened 1,160 women for HR HPV at the Educational Public Health Institute of Split and Dalmatia County, by using Hybrid Capture 2 HPV DNA test. Only HR HPV positive specimens determined by HC2 were further genotyped by polymerase chain reaction (PCR) based assay at the Department of Pathology and Forensic Medicine, Split.

Results: Out of the total number of tested women, 406 (35\%) of them were positive to HR HPV. The following frequency was observed: HPV 16 in $10.8 \%$, HPV 18 in $7.8 \%$, HPV 31 in 2.3\%, HPV 33 in $1.1 \%$, HPV 52 in $0.9 \%$, HPV 45 in $0.6 \%$, and HPV 59 in $0.4 \%$ specimens.

Conclusion: The data obtained from our study indicate that HPV 16 is the most common HPV type found in the cervical specimens among women of Southern Croatia, as in most studies worldwide, followed by HPV 18 and HPV 31. The positivity rates in our study slightly differed for HPV types 18 and 31 from those found in the other studies conducted in Northern Croatia. These suggesting geographic and environmental factors are related to the prevalence of HPV types. We consider it very important to gather information on regional variations in the HPV type spectrum.

Key words: HPV, high-risk genotypes, Dalmatia County, Croatia

Address for correspondence: V. Kaliterna, Department of Medical Microbiology and Parasitology, Educational Public Health Institute of Split and Dalmatia County, Vukovarska 46, 21000 Split, Croatia. E-mail: vanja.kaliterna@gmail.com

\section{INTRODUCTION}

Cervical cancer is the second most common cancer in women worldwide. There are about 490,000 newly registered cases every year. There are about 270,000 cervical cancer deaths in the world annually, $85 \%$ of which take place in developing countries because of absent or poor screening programmes. Infection with Human Papillomavirus (HPV) is the main cause of cervical cancer. HPV is also one of the most frequent causal agents of sexually transmitted diseases. It can cause various clinical conditions, from asymptomatic infections to benign and malignant diseases of the genital region. Luckily most HPV infections are spontaneously cleared by host immune response. At present, there are more than 200 known HPV types. More than 40 types attack the epithelium of the genital tract, and are transmitted mainly through sexual intercourse. The types that are most commonly related to the development of cervical cancer, so called oncogenic or high-risk types (HR HPV), are: 16, 18, 31, 33, 34, 35, 39, 45, 51, 52, 56, $58,59,66,68$ and $70(1-3)$.

Genital HPV infection is rarely reported (there is no legal obligation). While its worldwide prevalence is assumed to be higher than 20 million, the incidence of HPV infection in the United States ranges from 1 million to 5.5 million per year (2).
The prevalence of HPV DNA in cervical cancer cases is $99.7 \%$ (3), compared to $5 \%$ to $20 \%$ of cervical specimens in women without cervical cancer (4-6). HPV 16 and HPV 18 are associated with $70 \%$ of cervical cancer worldwide $(1,7)$. The prevalence and distribution of the different HPV types in cervical samples with normal cytology and low grade cervical lesions vary around the world (2).

Croatia has a lower cancer incidence than most Central and Eastern European countries. There are about 355 new cases (incidence rate 13.3/100,000), and about 100 deaths each year (mortality rate 5.0/100,000 women) (8).

Very little is known about prevalence and distribution of HPV types in Croatia. There are a few studies from Northern Croatia about HPV prevalence related only to cervical specimens of women with abnormal Pap smear (9-11). There is only one small scale study for Southern Croatia (Split and Dalmatia County) conducted by Kaliterna et al. related to cervical samples of women with either normal or abnormal Pap smear (12).

We decided to expand our research on this topic in a larger and more detailed study. The aim was to evaluate the prevalence of HPV types in the female population with either normal or abnormal Pap smears in Southern Croatia (Dalmatia County). To go further with this study we wanted to evaluate the distribution 
of HPV types and their association with different cytological findings (Pap smears).

\section{MATERIALS AND METHODS}

The study involved a total of 1,160 women who approached the Educational Public Health Institute of Split and Dalmatia County, during one year period, with a request for HPV testing. The age of the female participants ranged from 17 to 58 years (the average age being 30 years). The study population included all women referred by their gynecologists for HPV DNA testing to our laboratory, on the occasion of the general population survey (with either normal or abnormal cytological diagnosis). All women underwent examination performed by a gynecologist, and two cervical scrapings were collected, for cytology and detection of HPV DNA. Informed consent was obtained from all participants. The cytology was reported using Bethesda system, as atypical squamous cell of undetermined significance (ASCUS), low grade squamous intraepithelial lesion (LSIL), and high grade squamous intraepithelial lesion (HSIL). The information from the Pap smear results was used to examine the relationship between HPV infections and histologically diagnosed cervical lesions.

The study had been approved by a suitably constituted Ethics Committee of the institution within which the work was undertaken and it conforms to the provisions of the Declaration of Helsinki.

HR HPV was detected in cervical exfoliated cells, by using a Hybrid Capture 2 (HC2) DNA test (Qiagene Corporation, Gaithersburg, MD USA). The HC2 test was used in screening specimens for high risk HPV types $(16,18,31,33,35,39,45,51,52,56,58$, 59 and 68). This test had been approved by the FDA for detection of HPV DNA in cervical specimens for diagnostic purpose, but it can not differentiate individual HPV types within the group (2).

Only HR HPV positive specimens detected by the Hybrid capture test were sent for further genotyping at the Department of Pathology and Forensic Medicine, Split University Hospital and School of Medicine. DNA was extracted from cervical cells, by using reagents Nucleo Spin Tissue (Machery-Nagel, Düren, Germany). Genotypes were distinguished with polymerase chain reaction (PCR) based assays using primer sequences for HR HPV types: 16, 18, 31, 33, 45, 52, and 59. Positive and negative controls were included in each reaction. PCR reactions were performed according to the manufacturer instruction on PCR system (Applied Biosystems, Foster City, USA). PCR products were detected using agarose gel electrophoresis (3\% agarose gel). Clinical samples were checked for the integrity of the target DNA by standard amplification of the human $\beta$-globin, as described elsewhere. The specific primers for amplification of the sequence containing the E6 region of HPV types: 16, 18 and 33 were used (TaKaRa, Bio. Inc., Japan) (13). Amplification products yield DNA fragment of $140 \mathrm{bp}$ for HPV types: 16, 18 and $141 \mathrm{bp}$ for HPV type 33. The presence of HPV types: 31, 45, 52 and 59 was detected by using primers for amplification of the sequence containing the E7 region, described by Walboomers et al. (3), yielding a PCR product of $100 \mathrm{bp}$. Undetermined types were referred to as other types HPV.

Statistical analysis was carried out using Chi-square test $\left(\chi^{2}\right.$ test). The package SPSS 17.0 was used (SPSS Inc., Chicago, Ill., USA). Only $\mathrm{p}<0.05$ was considered statistically significant.

\section{RESULTS}

During routine HPV testing in Split and Dalmatia County, a total of 1,160 women with either normal or abnormal cytology were tested and $406(35 \%)$ of them were positive to HR HPV, when samples were assessed by the HC2 test. Among HPV positive women, $79(19.5 \%)$ were under 24 years of age, 197 (48.5\%) were $25-34$ years old, 82 (20.2\%) were $35-44$ years old, and 48 $(11.8 \%)$ were $\geq 45$ years old. Of these 406 HPV positive women, 24 (5.9\%) had no SIL, 186 (45.8\%) had ASCUS/LSIL, 148 (36.5\%) HSIL and 48 (11.8\%) had unknown cytology (Table 1).

Only HR HPV positive specimens by HC2 were further genotyped by PCR based assay. In this study a spectrum of seven HPV types were detected. Out of 1,160 tested women in our analysis, these are the frequencies of different genotypes: HPV 16 in $10.8 \%$, HPV 18 in $7.8 \%$, HPV 31 in 2.3\%, HPV 33 in $1.1 \%$, HPV 52 in $0.9 \%$, HPV 45 in $0.6 \%$, HPV 59 in $0.4 \%$, while $12.2 \%$ of all tested specimens remained with unresolved genotype (Table 2). Among $406 \mathrm{HPV}$ positive samples, HPV 16 was the most frequent type in $30.8 \%$ cases, followed by HPV $18(22.2 \%)$, HPV $31(6.7 \%)$, HPV 33 (3.2\%), HPV 52 (2.5\%), HPV 45 (1.7\%), and HPV 59 $(1.2 \%)$. While the other HPV types occurred at a frequency of $34.7 \%$ of positive specimens (Table 2). Multiple HPV infections were found in $12(3 \%)$ cases out of 406 positive specimens.

Among HPV positive women, HPV 16 was found to be the most prevalent type within each histological category $(37.5 \%$ among no SIL, 29.0\% ASCUS/LSIL, and 34.5\% HSIL), followed by HPV 18 (29.2\% among no SIL, 19.9\% ASCUS/LSIL, and $22.3 \%$ HSIL), HPV 31 (8.3\% among no SIL, 6.5\% ASCUS/LSIL, and $6.8 \%$ HSIL). The frequency of unresolved HPV types (other HPV types) was approximately the same in cervical specimens of women with ASCUS/LSIL and those with HSIL, 38.2\% and $29.7 \%$, respectively. In our study there were no significant differences in the prevalence of each HPV type regarding different histological finding $(\mathrm{p}=0.58)$ (Table 3 ).

As we expected, most of the HPV positive women have had abnormal cytological findings (45.8\% ASCUS/LSIL and 36.5\%

Table 1. Age distributions and cytological findings among HPV positive women $(n=406)$

\begin{tabular}{|l|c|}
\hline Years & $\mathrm{n}(\%)$ \\
\hline$\leq 24$ & $79(19.5)$ \\
\hline $25-34$ & $197(48.5)$ \\
\hline $35-44$ & $82(20.2)$ \\
\hline$\geq 45$ & $48(11.8)$ \\
\hline Total & $406(100.0)$ \\
\hline Cytology & $\mathbf{n}(\%)$ \\
\hline No SIL & $24(5.9)$ \\
\hline ASCUS/LSIL & $186(45.8)$ \\
\hline HSIL & $148(36.5)$ \\
\hline Unknown cytology & $48(11.8)$ \\
\hline Total & $406(100.0)$ \\
\hline
\end{tabular}

No SIL - without squamous intraepithelial lesion

ASCUS - atypical squamous cell of undetermined significance

LSIL - low grade squamous intraepithelial lesion

$\mathrm{HSIL}$ - high grade squamous intraepithelial lesion 
Table 2. HPV type specific prevalence among women in Southern Croatia (Dalmatia)

\begin{tabular}{|c|c|c|c|}
\hline \multirow[b]{2}{*}{ HPV type } & \multirow{2}{*}{$\begin{array}{l}\text { No. HPV positive } \\
\qquad N=406^{*}\end{array}$} & \multicolumn{2}{|c|}{ Percentage distribution of HPV types } \\
\hline & & $\begin{array}{l}\text { Whole population } \\
\qquad N=1,160\end{array}$ & $\begin{array}{c}\text { HPV positives } \\
N=406\end{array}$ \\
\hline 16 & 125 & 10.8 & 30.8 \\
\hline 18 & 90 & 7.8 & 22.2 \\
\hline 31 & 27 & 2.3 & 6.7 \\
\hline 33 & 13 & 1.1 & 3.2 \\
\hline 52 & 10 & 0.9 & 2.5 \\
\hline 45 & 7 & 0.6 & 1.7 \\
\hline 59 & 5 & 0.4 & 1.2 \\
\hline Other types & 141 & 12.2 & 34.7 \\
\hline
\end{tabular}

*Some women counted more than once because of multiple infections, which were found in 12 cases.

Table 3. HPV type specific prevalence in the group of patients with different cytological findings (PAP smear)

\begin{tabular}{|c|c|c|c|c|}
\hline HPV type & $\begin{array}{c}\mathrm{n}(\%) \text { of } \\
\text { no SIL cases } \\
\mathbf{N}=\mathbf{2 4}\end{array}$ & $\begin{array}{c}\mathrm{n}(\%) \text { of } \\
\text { ASCUS/ LSIL } \\
\mathbf{N}=186\end{array}$ & $\begin{array}{c}\mathrm{n}(\%) \text { of } \\
\text { HSIL } \\
\mathbf{N}=148\end{array}$ & $\begin{array}{c}\mathrm{n}(\%) \text { of unknown } \\
\text { cytology cases } \\
\mathbf{N}=48\end{array}$ \\
\hline 16 & $9(37.5)$ & $54(29.0)$ & $51(34.5)$ & $11(22.9)$ \\
\hline 18 & $7(29.2)$ & $37(19.9)$ & $33(22.3)$ & $13(27.1)$ \\
\hline 31 & $2(8.3)$ & $12(6.5)$ & $10(6.8)$ & $3(6.3)$ \\
\hline 33 & $2(8.3)$ & $5(2.7)$ & $5(3.4)$ & $1(2.1)$ \\
\hline 52 & & $7(3.8)$ & $3(2.0)$ & \\
\hline 45 & & $5(2.7)$ & $3(1.4)$ & \\
\hline 59 & $4(16.7)$ & $2(1.1)$ & $41(38.0)$ & \\
\hline Other types & & & & \\
\hline
\end{tabular}

$\left(X^{2}=19.03 ; s s=21 ; p=0.58\right)$

No SIL - without squamous intraepithelial lesion

ASCUS - atypical squamous cell of undetermined significance

LSIL - low grade squamous intraepithelial lesion

$\mathrm{HSIL}$ - high grade squamous intraepithelial lesion

HSIL) (Table 1), but no significant differences were found with regard to the frequency of abnormal cytology in relation to any individual HPV type. Out of the total of 125 HPV 16 positive specimens $7.2 \%$ had no SIL, $43.2 \%$ had ASCUS/LSIL, and $40.8 \%$ HSIL. Among 90 HPV 18 positive specimens $7.8 \%$ had no SIL, $41.0 \%$ had ASCUS/LSIL, and 36.7\% HSIL. Out of 27 HPV 31 positive specimens $7.4 \%$ had no SIL, $44.5 \%$ had ASCUS/LSIL, and $37.0 \%$ HSIL (Table 4).

\section{DISCUSSION}

HPV DNA has been identified in almost all cases of cervical cancer worldwide, with the most frequent types 16 and 18 in $70 \%$ of cases (14). In Europe, HPV prevalence in invasive cervical cancer is $85.9 \%$, in exfoliated cells of women with low grade lesions in Pap smears is $67.8 \%$, while in cervical specimens of women with normal cytology the HPV prevalence is $8.1 \%$ (7, $15,16)$.

At present, there is limited data regarding the prevalence and distribution of HPV types in Croatia. There are a few studies from Northern Croatia (Zagreb County), about HPV prevalence related only to cervical specimens of women with abnormal Pap smear. According to these studies, HPV prevalence in cervical specimens of women with abnormal Pap smears ranges from 58.8\% to $64.0 \%$, caused by the most common types: HPV $16(11.4 \%$ to $15.9 \%)$, HPV 31 (5\% to $8.7 \%)$, HPV 18 ( $2 \%$ to $3.8 \%)$, and HPV $33(2.7 \%$ to $2.8 \%)(9-11)$. There is only one small scale study (570 women) for Southern Croatia (Split and Dalmatia County) related to cervical samples of women with either normal or abnormal Pap smear. Out of the total number of tested women, 200 (35\%) of them were positive to HR HPV, with the most common types: HPV 16 in 10\%, HPV 18 in $6.1 \%$, HPV 31 in $2.6 \%$, and HPV 33 in $1.9 \%$ specimens (12).

In the present study, our research of this topic expanded and was conducted in more detailed way. The aim was to evaluate the prevalence of HPV types in the female population with any cytological findings in Southern Croatia (Dalmatia County) and to evaluate the distribution of HPV types and their association with different cytological findings (Pap smears). Similar to the results of our previous study, out of the total number $(1,160)$ of tested women, $35 \%$ (406) of them were HPV positive, with the most common types: HPV 16 in $10.8 \%$, HPV 18 in $7.8 \%$, HPV 31 in $2.3 \%$, and HPV 33 in $1.1 \%$ specimens. 
Table 4. Correlation between cytological findings and different HPV types

\begin{tabular}{|c|c|c|c|c|c|c|c|c|}
\hline Cytology & $\begin{array}{c}\mathrm{n}(\%) \text { of } \\
\text { HPV } 16 \text { cases } \\
\mathrm{N}=125\end{array}$ & $\begin{array}{c}\mathrm{n}(\%) \text { of } \\
\text { HPV } 18 \text { cases } \\
\mathrm{N}=90\end{array}$ & $\begin{array}{c}\mathrm{n}(\%) \text { of } \\
\text { HPV } 31 \text { cases } \\
\mathrm{N}=27\end{array}$ & $\begin{array}{c}\mathrm{n}(\%) \text { of } \\
\text { HPV } 33 \text { cases } \\
\mathrm{N}=13\end{array}$ & $\begin{array}{c}\mathrm{n}(\%) \text { of } \\
\text { HPV } 52 \text { cases } \\
\mathrm{N}=10\end{array}$ & $\begin{array}{c}\mathrm{n}(\%) \text { of } \\
\text { HPV } 45 \text { cases } \\
\mathrm{N}=7\end{array}$ & $\begin{array}{c}n(\%) \text { of } \\
\text { HPV } 59 \text { cases } \\
N=5\end{array}$ & $\begin{array}{c}\mathrm{n}(\%) \text { of } \\
\text { other types } \\
\mathrm{N}=141\end{array}$ \\
\hline No SIL & $9(7.2)$ & $7(7.8)$ & $2(7.4)$ & $2(15.3)$ & & & & $4(2.8)$ \\
\hline ASCUS/LSIL & $54(43.2)$ & 37 (41.1) & $12(44.5)$ & $5(38.5)$ & $7(70.0)$ & $5(71.4)$ & $2(40.0)$ & $71(50.4)$ \\
\hline $\mathrm{HSIL}$ & $51(40.8)$ & $33(36.7)$ & $10(37.0)$ & $5(38.5)$ & $3(30.0)$ & $2(28.6)$ & $3(60.0)$ & $44(31.2)$ \\
\hline Unknown & $11(8.8)$ & $13(14.4)$ & $3(11.1)$ & $1(7.7)$ & & & & $22(15.6)$ \\
\hline
\end{tabular}

$\left(X^{2}=19.03 ; s s=21 ; p=0.58\right)$

No SIL - without squamous intraepithelial lesion

ASCUS - atypical squamous cell of undetermined significance

LSIL - low grade squamous intraepithelial lesion

$\mathrm{HSIL}$ - high grade squamous intraepithelial lesion

Our results of HR HPV genotyping are slightly different from those found in the studies conducted in Northern Croatia. The frequency of HPV types in these studies are similar for HPV 16 (10.8 versus $11.4-15.9 \%$ ) and HPV 33 (1.1 versus $2.7-2.8 \%$ ), but discordant for HPV 18 (7.8 versus 2.0-3.8\%) and HPV 31 (2.3 versus $5.0-8.7 \%$ ). The prevalence of HPV type 18 in LSIL in Europe is $5.1 \%$, but ranges from $2.2 \%$ to $31.4 \%$ when compared by region (15). The reason for these discrepancies could be because (a) in previous studies regarding HPV prevalence in Northern Croatia, mainly women with abnormal Pap smears were tested for the presence of HPV. While in our study population included all women who were referred by their gynecologists for HPV DNA testing to our laboratory (with any cytological diagnosis), (b) the choice of type-specific primers for DNA amplification (different, but still clinically validated), and (c) different distribution of HR HPV types in both Counties. Split and Dalmatia County is an important tourist region of Croatia with a high number of tourists passing through. It is also a maritime centre with the port and significant number of seamen that are carriers of HPV types gained from all over the world and spread within this region.

In conclusion, the data obtained from our study indicate that HPV 16 is the most common HPV type found in the cervical specimens among women of Split and Dalmatia County as in most studies worldwide, followed by HPV 18 and HPV 31. The positivity rates by HPV type in our study slightly differed for HPV types 18 and 31 from those found in the other studies conducted in Northern Croatia, which suggests that geographic and environmental factors are related to the prevalence of HPV types.

Although it is important to have international updates on the prevalence and type distribution of HPV in the worldwide population, we consider it very important to gather information on regional variations in the HPV type spectrum, particularly in the context of HPV vaccine application. However, this data on the prevalence and distribution of HPV types in women with any cytology finding in Southern Croatia may contribute to increasing knowledge of the HPV epidemiology in Croatia.

\section{Conflict of Interest}

None declared

\section{REFERENCES}

1. Muñoz N, Bosch FX, de Sanjosé S, Herrero R, Castellsagué X, Shah $\mathrm{KV}$, et al; International Agency for Research on Cancer Multicenter
Cervical Cancer Study Group. Epidemiologic classification of human papillomavirus types associated with cervical cancer. N Engl J Med. 2003 Feb 6;348(6):518-27.

2. Burd EM. Human Papillomavirus and cervical cancer. Clin Microbiol Rev. 2003 Jan;16(1):1-17.

3. Walboomers JM, Jacobs MV, Manos MM, Bosch FX, Kummer JA, Shah $\mathrm{KV}$, et al. Human Papillomavirus is a necessary cause of invasive cervical cancer worldwide. J Pathol. 1999 Sep;189(1):12-9.

4. Bosch FX, de Sanjosé S. Chapter 1: Human Papillomavirus and cervical cancer - burden and assessment of causality. J Natl Cancer Inst Monogr. 2003;(31):3-13.

5. Arora R, Kumar A, Prusty BK, Kailash U, Batra S, Das BC. Prevalence of high-risk human papillomavirus (HR-HPV) types 16 and 18 in healthy women with cytologically negative Pap smear. Eur J Obstet Gynecol Reprod Biol. 2005 Jul 1;121(1):104-9.

6. Maehama T. Epidemiological study in Okinawa, Japan, of human papillomavirus infection of the uterine cervix. Infect Dis Obstet Gynecol. 2005 Jun;13(2):77-80.

7. Clifford GM, Smith JS, Plummer M, Muñoz N, Franceschi S. Human papillomavirus types in invasive cervical cancer worldwide: a metaanalysis. Br J Cancer. 2003 Jan 13;88(1):63-73

8. Znaor A, Strnad M. Cervical cancer in Croatia: state of the art and possibilities for prevention. Coll Antropol. 2007 Apr;31 Suppl 2:37-40.

9. Grce M, Husnjak K, Bozikov J, Magdić L, Zlacki M, Lukac J, et al. Evaluation of genital human papillomavirus infections by polymerase chain reaction among Croatian women. Anticancer Res. 2001 JanFeb;21(1B):579-84.

10. Halec G, Milutin Gasperov N, Sabol I, Matovina M, Grce M. Human papillomavirus types 52 and 58 among Croatian women. In: Proceedings in the Human Papillomavirus Infection and Global Prevention of Cervical Cancer; 2006 Apr 23-26; Paris. Paris: EUROGIN; 2006. p. 61.

11. Milutin-Gašperov N, Sabol I, Halec G, Matovina M, Grce M. Retrospective study of the prevalence of high-risk human papillomaviruses among Croatian women. Coll Antropol. 2007 Apr;31 Suppl 2:89-96.

12. Kaliterna V, Anđelinović Š, Pejković L, Drmić Hofman I. Human papillomavirus DNA typing in the cervical specimens among women of Split and Dalmatian County. Coll Antropol. 2007 Apr;31Suppl 2:79-82.

13. Shimada M, Fukushima M, Mukai H, Kato I, Nishikawa A, Fujinaga $\mathrm{K}$. Amplification and specific detection of transforming gene region of human papillomavirus 16, 18 and 33 in cervical carcinoma by means of the polymerase chain reaction. Jpn J Cancer Res. 1990 Jan;81(1):1-5.

14. De Sanjosé S, Quint WG, Alemany L, Geraets DT, Klaustermeier JE, Lloveras B, et al. Human papillomavirus genotype attribution in invasive cervical cancer: a retrospective cross-sectional worldwide study. Lancet Oncol. 2010 Nov;11(11):1048-56.

15. Clifford GM, Rana RK, Franceschi S, Smith JS, Gough G, Pimenta JM. Human papillomavirus genotype in low-grade cervical lesions: comparison by geographic region and with cervical cancer. Cancer Epidemiol Biomarkers Prev. 2005 May;14(5):1157-64.

16. De Sanjosé S, Diaz M, Castellsagué X, Clifford G, Bruni L, Muñoz N, et al. Worldwide prevalence and genotype distribution of cervical human papillomavirus DNA in women with normal cytology: a meta analysis. Lancet Infect Dis. 2007 Jul;7(7):453-9. 